Journal of Advanced Research in Fluid Mechanics and Thermal Sciences

\title{
Effects of Sterilization Times of Palm Bunches on Fruit-Bunch Separation, Crude Palm Oil Yield and Quality Using Direct Steaming
}

\author{
Siravit Pakdeechot ${ }^{1}$, Sherly Hanifarianty ${ }^{2}$, Makatar Wae-hayee ${ }^{1, *}$ \\ 1 Department of Mechanical Engineering, Faculty of Engineering, Prince of Songkla University, 90112 Hat Yai, Songkhla, Thailand \\ Sembawa Research Center, Indonesian Rubber Research Institute (IRRI), Jalan Raya Palembang-Pangkalan Balai KM. 29, P.O. BOX 1127, \\ Palembang, South Sumatera, 30001, Indonesia
}

ARTICLE INFO

Article history:

Received 25 August 2020

Received in revised form 15 January 2021

Accepted 16 January 2021

Available online 2 May 2021

\section{Keywords:}

Fresh fruit bunch (FFB); palm oil milling; crude palm oil (CPO); oil palm sterilization; steaming

\section{ABSTRACT}

In palm oil milling factory, Fresh Fruit Bunch (FFB) must undergo by sterilizing before processing oil extraction. In commercial industry, conventional sterilization units, a boiler and a sterilizer in steaming process, are separated. To minimize srerilization unit, a boiler and a sterilizer can be combined in one unit. Therefore, the aim of this work is to study ability to combine the boiler and the sterilizer in one unit. Palm fruit bunches were sterilized in a mini sterilizer by direct steaming at 2.5 bar for 30, 45, 60 and 70 minutes. The results show that a percentage of fruit-bunch separation and crude palm oil yield increased when sterilization time was longer. The trend of increasing crude palm oil yield was similar to the trend of increasing fruit-bunch separation. The suggested condition was at 60 minutes giving acceptable fruit-bunch separation, FFA and DOBI.

\section{Introduction}

Oil palm is commercial plantation which produce widely in Indonesia, Malaysia and Thailand. Based on a comparison of plantation area, a oil yield of oil palm is the largest as compared to a yield of other oily fruits. Palm oil fruit comprises 22.1 percent of oil yield when fully mature (Table 1). The Maturity index of palm oil fruit can affect the oil yield and free fatty acid (FFA). Processing palm oil fruit without delay could produce 87 percent of oil extraction and a good quality FFA reaching 2.31 percent [1]. FFA intended for commercial purposes should not exceed 5 percent [2]. Therefore, it is important to process palm oil fruit immediately after harvesting $[3,4]$. The FFA percentage could increase due to a long storage period which results in damaged fruit [5-8] while high FFA in vegetable oil generally indicates the poor process that causes the breakdown of triglyceride after refining [9].

After harvesting fresh fruit bunches (FFB), the bunch need to be delivered to a milling factory immediately or not more than 24 hours. The bunchs are undergoing sterilizing to minimize low quality oil palm from increasing FFA. Therefore, sterilization plays an important role in palm oil milling processing [11]. The Sterilization process uses steam with pressure at 40 psi $\left(140^{\circ} \mathrm{C}\right)$ for $75-90$

\footnotetext{
* Corresponding author.

E-mail address: makatar.w@psu.ac.th
}

https://doi.org/10.37934/arfmts.82.2.3946 
minutes [12]. The purposes of sterilization include softening the bunch, facilitating the fruit release from the bunch, enzyme inactivation, reducing the water content in the fruit and facilitating oil extraction $[13,14]$.

Table 1

\begin{tabular}{lll}
\multicolumn{3}{l}{ Oil yield and FFA for each maturity level of oil palm [10] } \\
\hline Fruit maturity & Oil yield (\%) & FFA (\%) \\
\hline Immature fruit & 16 & 1.6 \\
Half-mature fruit & 21.4 & 1.7 \\
Mature fruit & 22.1 & $1.8-2.1$ \\
Over-mature fruit & 21.9 & $2.6-3.8$ \\
\hline
\end{tabular}

During the sterilization process, the moisture is influenced by steam which chemically breaks down resin and starch causing oil to foam. Poor sterilization might be caused by secondary oxidation that leads to discoloration of palm kernel and deterioration of bleaching index (DOBI). A.A. Hadi et al., [15] studied a sterilization process of FFB in a mini sterilizer operating at a pressure of 2.6 bar and saturation steam temperature at $140^{\circ} \mathrm{C}$ with different sterilization time for $40,50,60$ and 70 minutes. The study focuses on a total number of loose fruits which were detached from the bunch after sterilization process and the percentage of total loose fruits per the estimated total fruits for one bunch. The results suggests that total stripping of loose fruits from the stalk after sterilizing manual hand threshing procedure from the bunch occurs at sterilization time 70 minutes, whereas at 60 minutes the percentage of loose fruits obtained is close to $90 \%$ the estimated percentage detached loose fruit obtained at 60 minutes which is $90 \%$ is considered to be adequate as the minimum amount of loose fruit remaining in the bunch to be considered as empty bunch is $10 \%$ [16]. Sukaribin and Khalid [17] studied an effectiveness of sterilization of oil palm bunch using microwave heating. A power of microwave heating was varied at $1,1.5$ and $2 \mathrm{~kW}$. They explained that show that the heating of microwave are required to achieve better stripping efficiency and the sterilization can be done at shorter time by increasing the microwave power level. Umudee et al., [18] reported that drying oil palm by using microwave at $50-80^{\circ} \mathrm{C}$ which is the optimum temperature range for heating oil palm. In commercial industry, there are several sterilization types using steaming such as horizontal sterilizer [19], vertical sterilizer [20] and continuous sterilizer [21].

A palm oil milling factory requires a large amount of energy consumption during the processing. The sterilization process is the highest energy consumption as compared to other processes, especially, producing steam in boiler. As aforementioned steaming sterilization types, the boiler and the sterilizer is separated in each unit. This is affected in term of heat losses in steaming, piping and sterilizing processes. To minimize these heat losses, a boiler and sterilizer can be combined in one unit. Therefore, this work focus on ability to combine the boiler and sterilizer in the same unit.

The aim of this work is to investigate sterilization of palm fruit bunch by direct steaming in mini sterilizer which was combined the boiler and sterilizer in one unit. The effect of sterilization time on fruit-bunch separation and crude palm oil yield and quality was examined.

\section{Methodology}

\subsection{FFB Preparation}

FFB samples using throughout the experiments were obtained from the same palm plantation, belong to the Natural Resources Faculty, Prince of Songkla University (PSU), located about $40 \mathrm{~km}$ away from our laboratory at PSU. This FFB plantation has a mix of pisifera, tenera and dura pakm species, at approximately 10 years of age. Ripe FFB samples were cropped manually and carfully 
avoided scratching or bruising, and were brought directly to our laboratory in around 45 minutes of transport. All samples studied were re-cropped consistently without storage. The weight of each FFB sample was approximately $10 \mathrm{~kg}$. 2 bunches were sterilized in one experimental run, and 3 replications were done for one case with averaging the results.

\subsection{Experimental Apparatus}

The schematic diagram of FFB sterilization using in this work is shown in Figure 1 . The mini sterilizer of FFB by direct steaming was build up of metal sheet with an inner diameter of $35 \mathrm{~cm}$, a height of $60 \mathrm{~cm}$ and a volume of 58 liters. A fiber glass insulator was covered the sterilizer externally for minimizing heat losses to environment. A grille was assembled internally at the bottom for separating boiling water and FFB with a height of $2 \mathrm{~cm}$ from the base. A pressure gauge and pressure relief valve for controlling pressure in the sterilizer were assembled the sterilizer cover. The pressure was constant at 2.5 bar \pm 0.2 bar while sterilization time was varied at $30,45,60$ and 75 minutes, including initial heating. A T-type thermocouple for measuring steam temperature were located at the center of sterilizer. LPG was used as fuel for boiling water by burning at the bottom of sterilizer. A rotameter was used to control LPG flow rate. In this study, FFBs were selected 3 bunchs for every conditions with similar size, weight and ripeness.

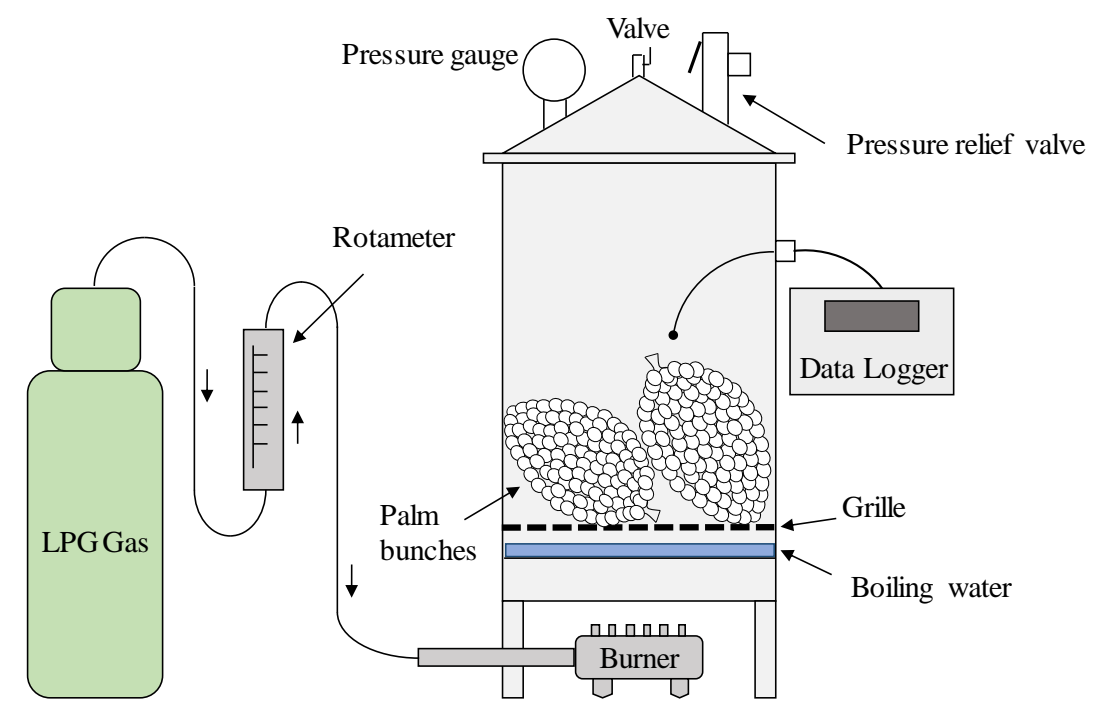

Fig. 1. A mini sterilizer for steaming palm bunched

\subsection{Palm Fruit Bunch Separation}

A schematic diagram of bunch-fruit separator was shown in Figure 2. Pins with $7 \mathrm{~cm}$ length were assembled in internal surface of $96-\mathrm{cm}$-diameter cylindrical metal and rotating disk. The rotating disk was rotated by 7.5-HP electric motor associated with gear box with constant rotation speed of 70 $\mathrm{rpm}$. The bunch was crashed lateral pins by centrifugal force of rotation disk. The FFBs after sterilizing was loaded suddenly into the bunch-fruit separator. To evaluate a percentage of bunch-fruit separation, the operating time of every case was fixed at 1 minutes. 

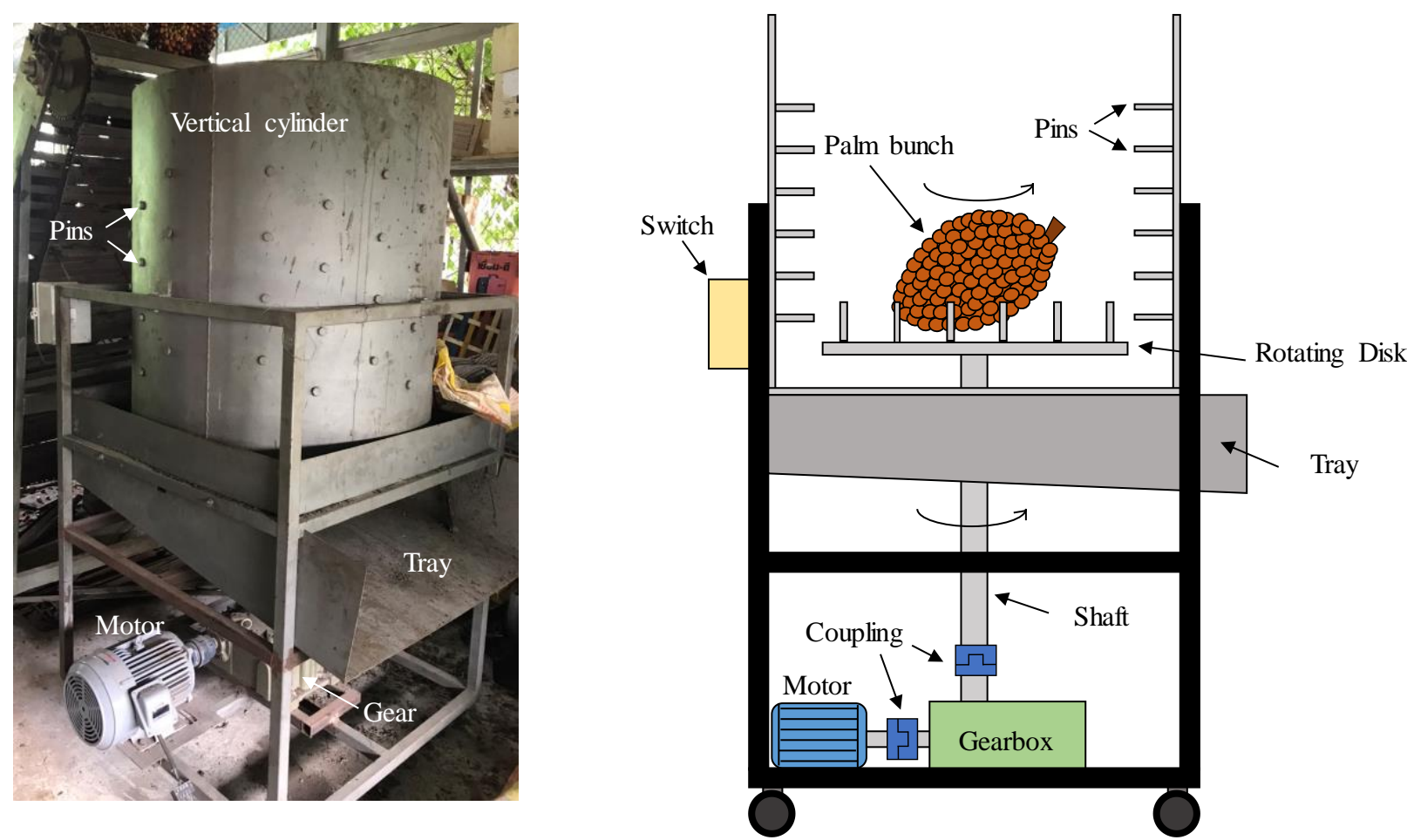

Fig. 2. A photo and schematic diagram of bunch-fruit separator

Percentage of bunch-fruit separation was using following Eq. (1)

$\eta_{M}=\frac{M_{1}-M_{2}}{M_{1}}(100 \%)$

where $\eta_{M}$ was the percentage of bunch-fruit separation by weighing (\%), $M_{1}$ was the total weight of palm fruit bunch (Kg), $M_{2}$ was the weight of palm fruit bunch including palm fruits without separation (Kg)

\subsection{Yield and Quality of Crude Palm Oil}

The palm fruits after separating from bunch were extracted by using screw extraction machine (Model VIC-1, Henan Vic Machinery Co. Ltd, Chaina). This machine can separately extract crude palm oil from mesocarp without breaking palm shell. This means that kernel crude palm oil was not extracted in this process. The capacity of production was $500 \mathrm{~kg} / \mathrm{h}$ of palm fruits driving by $10-\mathrm{HP}$ electric motor. In the process, the sterilized palm fruits were pressed by screw press. Crude palm oil was extracted through the small holes of screw cylinder, and shells with kernel including palm cake (Fiber of mesocarp) were delivered at the exit. The crude palm oil was filtered and weighed to evaluate the yield.

Percentage yield of crude palm oil compared to total weight of FFB was determined using following Eq. (2) [22]

$\eta_{m}=\frac{m_{1}}{m_{2}}(100 \%)$

where $\eta_{m}=$ Percentage yield of crude palm oil (\%), $m_{1}=$ the weight of crude palm oil $(\mathrm{g}), m_{2}=$ total weight of FFB (g) 
After obtaining crude palm oil, 5 grams of each sample were titrated to evaluate FFA by three replications. [23] Chemical used in this titration was ethanol, sodium hydroxide and phenolphthalein. The FFA evaluation was determined using following Eq. (2) [22]

$\% F F A=\frac{(S)(0.1)(25.6)}{m}$

where $\% F F A=$ Free Fatty Acid (\%), $S=$ Amount of sodium used $(\mathrm{ml}), m=$ the sample of crude palm oil (g). In order to evaluate Deterioration of Bleachability Index (DOBI), a CPO sample was examined using UV-Visible spectrophotometer (Shimadzu, UV-1601, Japan).

\section{Results and Discussions}

\subsection{Fruit-Bunch Separation}

Visual appearances of Fresh Fruit Bunches (FFB) before and after separation are shown in Table 2. At 30 minutes of sterilization, more fruits remained on the bunch than in the other cases. Remaining fruits were bruised and broken due to hitting against the pins in the fruit-bunch separator, because bunch is not softened enough by the sterilization process. At the longer steaming times (45, 60 and 75 minutes), amount of fruits remaining was lesser, and there was a small amount of bruised and broken fruits. It can be seen that the physical conditions of the separator functioned well when sterilization time was longer than 45 minutes.

Table 2

Comparison of Fresh Fruit Bunch (FFB) and the bunchs after splitting

\begin{tabular}{|c|c|c|c|c|}
\hline Bunch type & 30 minutes & 45 minutes & 60 minutes & 75 minutes \\
\hline FFB & & & & \\
\hline $\begin{array}{l}\text { Bunch after } \\
\text { splitting }\end{array}$ & & & & \\
\hline
\end{tabular}

Percentage of fruit-bunch separation of sterilized bunch which was evaluated from Eq. (1) is shown in Figure 3. At 30 minutes of sterilization, the percentage of fruit-bunch separation were much lower than in other cases. The values increased significantly from 30 minutes to 45 minutes. At longer times than 45 minutes, percentage of fruit-bunch separation gradually increased. These results are similar to those of Ab Hadi et al., [24], using a small horizontal conventional sterilization system. According to Malaysian Palm Oil Board (MPOB) standard [16], the acceptance of fruit-bunch separation requires $90 \%$ of fruits released from the bunch as indicated by the horizontal dashed line in Figure 3. So, in this work, acceptable conditions were 60-75 minutes. These conditions match 
previous studies of steaming using a horizontal sterilizer, a vertical sterilizer, and a continuous sterilizer [18-21].

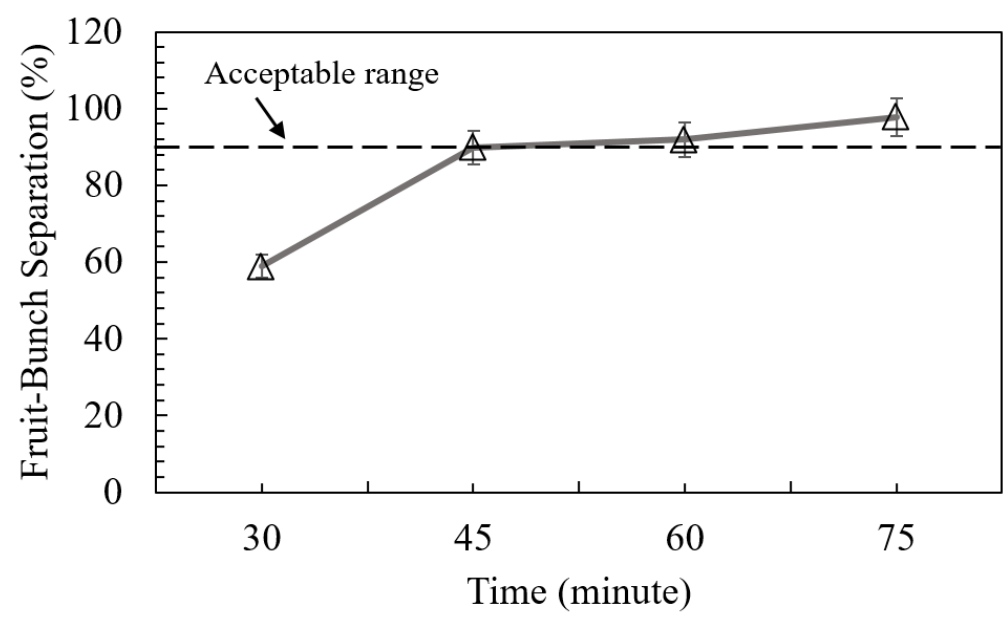

Fig. 3. Percentage of fruit-bunch separation of sterilized bunch

Generally, in large milling factory, the sterilization time is between $45-60$ minutes. After that sterilized palm bunches are loaded in a crusher machine for separating palm fruits from the bunches. In this work, sterilization by direct steaming between 60-75 minutes shown the potential of applying this technique with no degradation in term of splitting the palm fruits from the bunch.

\subsection{CPO Yield}

The yield of crude palm oil (CPO) calculated from Eq. (2) is shown in Figure 4. CPO increased with sterilization time. These results provide important insights: prolonging the sterilization time can increase CPO yield. at all choices of sterilization pressure. This corresponds to the percentage of fruitbunch separation as previously shown in Figure 3 , in which the percentages of fruit-bunch separation inxreased with prolonging the sterilization time.

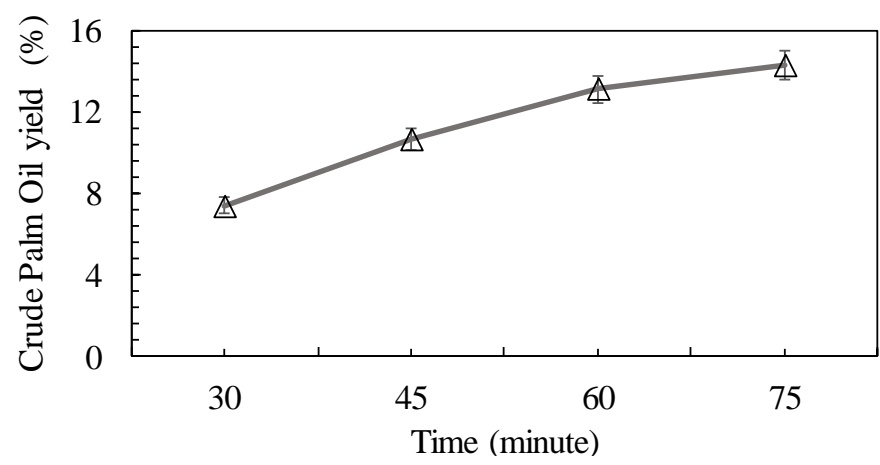

Fig. 4. CPO yield of sterilization palm

Usually, the yield of crude palm oil (CPO) is acceptable range at higher than $17 \%$, but the result from this study is lower that $15 \%$. It can be explained that, a $500 \mathrm{~kg} / \mathrm{h}$ screw press was used in this work to imitate small-scale palm oil mill operation. With a smaller oil palm sample (About $20 \mathrm{~kg}$ of FFB and $10-18 \mathrm{~kg}$ of fruitlet palms) than that used in a screw press, the insufficient pressing by the machine left CPO remaining in the palm cake. This is the reason for the low oil yield. 


\subsection{CPO Quality}

In order to assess the CPO quality in this work, Free Fatty Acid (FFA) content and Deterioration of Bleachability Index (DOBI) were determined. Based on the Malaysian Palm Oil Board (MPOB) standards, quality specifications of CPO require maximum $5 \%$ for FFA and minimum $2.3 \%$ for DOBI $[14,19,25]$. FFA and DOBI of CPO in this work are shown in Table 3. It is apparent that in all cases the FFA content was less than 5 percent and DOBI was larger than 2, which are acceptable by the standard specifications for CPO.

Table 3

FFA and DOBI of CPO extracted from sterilization palm

\begin{tabular}{lllll}
\hline & 30 minutes & 45 minutes & 60 minutes & 75 minutes \\
\hline FFA & 1.60 & 1.64 & 1.44 & 1.51 \\
DOBI & 4.10 & 4.22 & 4.36 & 4.39 \\
\hline
\end{tabular}

\section{Conclusions and Suggestion}

In this research, palm bunches were sterilized by direct steaming in mini sterilizer. Sterilization time was varied at 30, 45, 60 and 75 minutes while the pressure was fixed at 2.5 bar. The results were concluded as follow

i. Percentage of fruit-bunch separation and crude palm oil yield increased when sterilization time was longer.

ii. CPO quality was assessed in terms of free fatty acid (FFA) content and deterioration of bleachability index (DOBI) that were acceptable by commercial CPO quality standards.

iii. The results from this work for direct steaming are concordant with published results for conventional sterilization.

iv. The suggested condition was 60 minutes giving acceptable fruit-bunch separation, FFA and DOBI.

\section{Acknowledgement}

This work was financially supported by the Research Development Office (RDO) of Prince of Songkla University, Grant No. ENG610585S.

\section{References}

[1] Badmus, G. A. "NIFOR automated small scale oil palm fruit processing equipment. Its needs, development and cost effectiveness." In PORIM International Palm Oil Conference. Progress, Prospects Challenges Towards the 21st Century. Chemistry and TechnologySeptembe 9-14Kuala Lumpur, Malaysia, no. L-0218. PORIM, 1993.

[2] Nor'aini, S., and W. L. Siew. "Quality control measures in the palm oil industry." Palm Oil Dev (1990).

[3] Oo, Khaik-Cheang, Sau-Keen Teh, Hun-Teik Khor, and Augustine SH Ong. "Fatty acid synthesis in the oil palm (Elaeis guineensis): Incorporation of acetate by tissue slices of the developing fruit." Lipids 20, no. 4 (1985): 205-210. https://doi.org/10.1007/BF02534189

[4] Hudzari, M. Razali, Wan Ishak Wan Ismail, Abd. Rahman Ramli, Md. Nasir Sulaiman, Mohd Haniff Harun. "Colour for Agriculture Product in Al-Quran." In Proceeding of $2^{\text {nd }}$ International Conference on Islamic Science and Technology", ISTech 2010, 2010. https://doi.org/10.9735/0975-3710.2.2.21-27

[5] Fatin, S. A., S. Rosnah, and R. Yunus. "Effect of chopping oil palm fruit spikelets on the free fatty acid content release rate and its mechanical properties." International Journal of Research in Engineering and Technology 3, no. 1 (2014): 511-516. https://doi.org/10.15623/ijret.2014.0301086

[6] Fatin, S. A., S. Rosnah, and R. Yunus. "Effect of chopping oil palm fruit spikelets on the free fatty acid content release rate and its mechanical properties." International Journal of Research in Engineering and Technology 3, no. 1 (2014): 511-516. https://doi.org/10.15623/ijret.2014.0301086 
[7] Zu, K. S. A., Adjei-Nsiah, S., and Bani, R. J. "Effect of processing equipment and duration of storage of palm fruits on palm oil yield and quality in the Kwaebibrem District, Ghana." Agric. Res. Rev 1, (2012): 18-25.

[8] Rajanaidu, N., and B. K. Tan. "Variability of fatty acid composition (FAC) within bunches in the oil palm, Elaeis guineensis." Oleagineux 38, no. 11 (1983): 581-584.

[9] Copeland, Dick, and W. Maurice Belcher. "Methods for refining vegetable oils and byproducts thereof." U.S. Patent 6,172,248, issued January 9, 2001.

[10] Mangoensoekarjo, Soepadiyo, and Haryono Semangun. "Manajemen agrobisnis kelapa sawit." UGM-Press, Yogyakarta (2003).

[11] Jusoh, Junaidah Mat, Norizzah Abd Rashid, and Zaliha Omar. "Effect of sterilization process on deterioration of bleachability index (DOBI) of crude palm oil (CPO) extracted from different degree of oil palm ripeness." International Journal of Bioscience, Biochemistry and Bioinformatics 3, no. 4 (2013): 322.

[12] Sivasothy, K. "Palm oil milling technology." Advances in oil palm research, Vol. 1 (2000): 744-782.

[13] Mahidin, M. R. "Quality improvement in the production of Malaysian palm oil." Palm Oil Development 9 (1998): 1521.

[14] Hadi, S., D. Ahmad, and F. B. Akande. "Determination of the bruise indexes of oil palm fruits." Journal of food engineering 95, no. 2 (2009): 322-326. https://doi.org/10.1016/i.jfoodeng.2009.05.010

[15] Ab Hadi, A. B., and M. S. Takriff. "Determination of optimum sterilisation condition based on calculated heat transfer rate for palm oil mill process." ARPN Journal of Engineering and Applied Sciences 11, no. 13 (2016): 84758480.

[16] Malaysian Palm Oil Board (MPOB). "Fresh fruit bunch (FFB) grading manual. Kuala Lumpur: Malaysian Palm Oil Board." (2003).

[17] Sukaribin, Nazarulhisyam, and Kaida Khalid. "Effectiveness of sterilisation of oil palm bunch using microwave technology." Industrial Crops and Products 30, no. 2 (2009): $179-183$. https://doi.org/10.1016/i.indcrop.2009.05.001

[18] Umudee, I., M. Chongcheawchamnan, M. Kiatweerasakul, and C. Tongurai. "Sterilization of oil palm fresh fruit using microwave technique." International Journal of Chemical Engineering and Applications 4, no. 3 (2013): 111. https://doi.org/10.7763/IJCEA.2013.V4.274

[19] Han, Ng Mei, Choo Yuen May, and Ma Ah Ngan. "Dry heating of palm fruits: effect on selected parameters." American Journal of Engineering and Applied Sciences 5, no. 2 (2012): 128-131. https://doi.org/10.3844/ajeassp.2012.128.131

[20] Reese, Charles D. Industrial safety and health for administrative services. CRC Press, 2008. https://doi.org/10.1201/9781420053838

[21] Kandiah, Sivasothy, Yusof Basiron, A. N. H. A. R. Suki, Ramli Mohd Taha, and Y. H. Tan. "Continuous sterilization: The new paradigm for modernizing palm oil milling." J. Oil Palm Res (2006): 144-152.

[22] Pootao, Sunisa, and Kobsak Kanjanapongkul. "Effects of ohmic pretreatment on crude palm oil yield and key qualities." Journal of Food Engineering 190 (2016): 94-100. https://doi.org/10.1016/j.jfoodeng.2016.06.021

[23] Alimalbari, Ameen, Sherly Hanifarianty, Anil Kumar, Thanet Khomphet, Theera Eksomtramage, and Makatar Waehayee. "Effects of pressed palm conditions on acceleration of palm drying rate and CPO quality." Journal of Advanced Research in Fluid Mechanics and Thermal Sciences 55, no. 1 (2019): 12-19.

[24] Ab Hadi, A., Mohummad, A.W., Takriff, M.B., "Determination of optimization condition based om calculated heat transfer rate for palm oil mill process." APRN J. Eng. and App. Scie. 11 (2016): 8475-8480.

[25] Vincent, Christine Jamie, Rosnah Shamsudin, and Azhari Samsu Baharuddin. "Pre-treatment of oil palm fruits: A review." Journal of Food Engineering 143 (2014): 123-131. https://doi.org/10.1016/i.jfoodeng.2014.06.022 